\title{
A critical re-evaluation of bone surface modification models for inferring fossil hominin and carnivore interactions through a multivariate approach: Application to the FLK Zinj archaeofaunal assemblage (Olduvai Gorge, Tanzania)
}

\author{
Manuel Domínguez-Rodrigo ${ }^{\mathrm{a}, \mathrm{b}, *}$, Henry T. Bunn ${ }^{\mathrm{c}}$, José Yravedra ${ }^{\mathrm{b}}$ \\ a IDEA (Instituto de Evolución en África), Museo de los Orígenes, Plaza de San Andrés 2, 28005 Madrid, Spain \\ ${ }^{\mathrm{b}}$ Department of Prehistory, Complutense University, Prof. Aranguren s/n, 28040 Madrid, Spain \\ ${ }^{\mathrm{c}}$ Department of Anthropology, University of Wisconsin-Madison, 1180 Observatory Drive, Madison, WI 53706, USA
}

\section{A R T I C L E I N F O}

Article history:

Available online $\mathrm{xxx}$

\begin{abstract}
A B S T R A C T
Over the past three decades, controversial interpretations of the behavioral meaning of bone surface modifications at FLK Zinj regarding primary or secondary access to carcasses by hominins have stemmed from the independent use of mark types (cut, percussion, and tooth marks) to evaluate opposing models. Such controversy has also been based on an over-reliance on tooth mark frequencies (mostly generated by non-hominin carnivores), which have been documented to be high when hyenids are primary bone modifiers, low when felids have primary access to carcasses, and high when suids feed primarily or secondarily on carcass parts. In addition, it has also been argued that the frequency of tooth marks on the FLK Zinj bones has been overidentified by some researchers, by mistaking tooth marks with biochemical marks created by plant roots. Some methodological approaches have hampered the use of cut marks to identify hominin behavior. Most of the reasons for purported equifinality of experimental scenarios are strictly methodological and are also caused by the separate rather than joint analysis of mark types. In the present work, for the first time cut marks, tooth marks, and percussion marks will be jointly analyzed, both experimentally and at FLK Zinj. Primary and secondary access to carcasses by hominins yields different frequency associations of all of these marks, which can be diagnostic of the type of access. Such mark-type relationships can only be detected when all mark types are analyzed simultaneously and not as separate sets. This multivariate approach provides a robust interpretation of primary access to carcasses by hominins at FLK Zinj.
\end{abstract}

(c) 2013 Elsevier Ltd and INQUA. All rights reserved.

\section{Introduction}

Little can be interpreted of early human behavior without the analysis of bone surface modifications from early archaeofaunal assemblages. Although there is a general agreement as to what the criteria for distinguishing different types of marks should be (see Fisher, 1995; Domínguez-Rodrigo et al., 2007a), some controversy still exists regarding the extent of overlap of mark morphology in modifications created by different agents (see Domínguez-Rodrigo et al., 2010a, 2011a, 2011b; Njau, 2012). Potential equifinality between different taphonomic agents is frequently caused by the use

\footnotetext{
* Corresponding author. Department of Prehistory, Complutense University, C/ Prof. Aranguren s/n, Fac. Geography and History, 28040 Madrid, Spain.

E-mail address: m.dominguez.rodrigo@gmail.com (M. Domínguez-Rodrigo).
}

of single-variable (mark morphology) or double-variable (mark morphology and presence/absence of microstriations) approaches (e.g., Njau, 2012), which have been shown to be insufficient for correctly determining agency in bone surface modifications (e.g., Domínguez-Rodrigo et al., 2009). Furthermore, ambiguity is stressed when abandoning microscopic criteria and relying on macroscopic features (e.g., Njau, 2012). Several experimental studies show that multivariate approaches using microscopic criteria can correctly diagnose agent(s) when analyzing bone surface modifications (Domínguez-Rodrigo et al., 2009; Galán et al., 2009; De Juana et al., 2010; Baquedano et al., 2012).

Most importantly, equifinality is properly evaluated only through experimental research. This type of actualistic research was initially used to differentiate hominins and carnivores in their interaction in the formation and modification of bone assemblages. Blumenschine $(1988,1995)$ experimentally replicated hominin-

1040-6182/\$ - see front matter (c) 2013 Elsevier Ltd and INQUA. All rights reserved. http://dx.doi.org/10.1016/j.quaint.2013.09.042 
carnivore (Hammerstone-only [HO]) and carnivore-only (CO) models based on the distribution of tooth marks per bone portion. With this experimental framework, Blumenschine (1991, 1995) posited that early humans at the 1.84 Ma site of FLK Zinj (Olduvai Gorge) were passive scavengers. This approach was followed by some other scholars (Selvaggio, 1994; Capaldo, 1995), ${ }^{1}$ who strongly disagreed on how to interpret the resulting marks, and more specifically, on the behavioral meaning of butchery marks (Capaldo, 1998a; Selvaggio, 1998a). This contributed to the marginalization of butchery marks as useful taphonomic indicators of hominin behavior, despite their prominent role in some models (Bunn, 1981, 1983; Bunn and Kroll, 1986, 1988; Domínguez-Rodrigo and Pickering, 2003; Pickering and Domínguez-Rodrigo, 2006), based on the argument that they were subject to equifinality (Blumenschine, 1991; Capaldo, 1995, 1997). The butchery experimental models made by Capaldo (1995) and Selvaggio (1994) were subsequently questioned (see critical review in DomínguezRodrigo, 2009), because in their elaboration, a heterogeneous set of variables was used but was not demonstrated to be applicable to early hominins (e.g., due to the use of metal knives or unnecessary scraping of periosteum from bones during cut mark experiments) or had methodological problems (e.g., mark tallying per bone portion rather than mark location). One of the drawbacks of Blumenschine's original experiments was that the dispersion of data in some of the samples was too high because of small sample sizes, creating strong sample overlaps and rendering them of limited value for discriminating between experimental scenarios.

In recent work, Pante et al. (2012) reinstated Blumenschine's (1995) original model that hominins at FLK Zinj were passive scavengers from felid kills. They did so by bootstrapping their former carnivore experimental samples to reduce sample dispersion, adding a new three-patterned model (vulture-hominincarnivore $[\mathrm{V}-\mathrm{H}-\mathrm{C}]$ ) and comparing the results to their previously criticized interpretation of bone surface modifications from this site (Domínguez-Rodrigo et al., 2007a; Domínguez-Rodrigo and Barba, 2006, 2007). In their approach to the FLK Zinj fossil assemblage, Pante et al. (2012: 405) argue that their interpretation is "consistent with new information that specifies the paleolandscape setting of FLK 22, included a lightly wooded peninsula at which hominins might have acquired tree-stored leopard kills, and an adjacent wetland at which carnivores seem to have ambushed prey and left scavengeable carcasses that could be exploited by hominins" (Blumenschine et al., 2012). This new paleoecological interpretation contradicts Blumenschine and Masao's (1991) former reconstruction of the FLK Zinj as a locus in the middle of a barren lakemargin mudflat. Such a paleoecological reconstruction of the site, as a wooded environment close to a spatially-restricted wetland created by a freshwater spring, is not new because it was first proposed by Ashley et al. (2010). Domínguez-Rodrigo et al.'s (2010b) sampling of several thousands of square meters of the paleolandscape surrounding the FLK Zinj site, documented no significant presence of carnivore-modified bones in the environment, which argues against a productive carcass-yielding landscape as would be expected if carnivore presence were as important as suggested by Pante et al. (2012).

Pante et al.'s (2012) new interpretations are also contradictory mainly because these authors have not provided an interpretation that could jointly explain the frequencies of tooth, percussion, and cut marks documented at FLK Zinj. When considering percussion marks alone, Pante et al. (2012: 403) claim that "the incidence of percussion marking at FLK 22 is most similar to the $\mathrm{H}-\mathrm{C}$ [Hominincarnivore] model for size group $1-2$ and the $\mathrm{V}-\mathrm{H}-\mathrm{C}$ model for size group 3-4". This is inaccurate: the incidence of percussion marks on bones from large animals at the site falls equally between the 95\% c.i. (confidence interval) variation range of the Hammerstoneonly ( $\mathrm{HO}$ ) and the $\mathrm{V}-\mathrm{H}-\mathrm{C}$ model for large carcasses. Either way, it shows that all or most bones were broken by hominins at the site.

When looking at tooth marks, Pante et al. (2012: 404) claim that "the incidence of tooth marking in the FLK 22 assemblage is consistent with carnivores, not hominins, having had primary access to flesh", despite the fact that their interpretation of tooth mark frequencies at FLK Zinj falls outside all of their experimental groups that also include percussion marks and the carnivore-only group. Pante et al. (2012) recognize this in part when they cite Selvaggio's (1998b) carnivore-to-hominid-to-carnivore model, where tooth mark frequencies on mid-shafts (54.2\%) are similar to those reported by them at FLK Zinj. This model implies complete or almost complete defleshing of carcasses by carnivores prior to hominin access. Furthermore, even if it is generally applied to all carcass sizes by Pante et al. (2012), this model can only be applied to small-sized carcasses, which constitute the bulk of Selvaggio's sample. ${ }^{2}$

Subsequently, Pante et al. (2012) deal with their more problematic type of bone surface modification, cut marks, by ignoring experiments showing how these marks can be used to discriminate primary from secondary access (See review in Domínguez-Rodrigo et al., 2007a). The high frequency of cut marks at FLK Zinj is difficult to interpret for these authors because it is not possible to know "whether this reflects defleshing of whole muscle masses or only the still attractive scraps that typically remain after mammalian carnivore defleshing......cut mark frequencies have not been shown to be sensitive to the amount of flesh remaining on bones" (Pante et al., 2012: 404). This statement ignores a substantial amount of experimental research that shows the opposite. Pante et al. make the preposterous claim that analyses and reconstructions by Bunn of significant defleshing of large bovids at FLK Zinj “... lacked a statistical and actualistic foundation.” Experiments reported by Domínguez-Rodrigo (1997a, 1997b) and Domínguez-Rodrigo et al. (2007a) provide evidence that when quantifying cut marks according to element type, bone section, and exact location of marks, primary and secondary access can be differentiated. When these referential frameworks are applied to the FLK Zinj cut mark data, access to fleshed carcasses is supported. These arguments and the subsequent interpretation of Zinj remain uncontradicted by Pante et al.'s recent evaluation of FLK Zinj.

Despite this important omission, Pante et al. (2012:404) argue (contra Blumenschine, 1995) that cut marks indeed indicate earlier access to carcasses than previously suggested (e.g., Blumenschine, 1986): the abundance of cut marks "indicates that hominins were typically acquiring carcasses after carnivores had defleshed at least the upper hindquarters" (emphasis added), because "cut marking on humeral midshaft fragments [at Zinj] is significantly greater than on femoral midshaft fragments" and this is "predicted by Blumenschine's (1986) carcass consumption sequence, which demonstrates that carnivores typically consume the higher yielding upper hindquarter flesh prior to forequarter flesh". Therefore, Pante

\footnotetext{
1 Capaldo (1995) experimented with "Hammerstone-to-Carnivore" and "WholeBone-To-Carnivore" models, replicating primary access to carcasses by humans and subsequently rejecting this option for lower Pleistocene hominins. Selvaggio (1994) modeled a Carnivore-to-Hominid-to-Carnivore scenario, supporting that carnivores preceded hominins in carcass exploitation at FLK Zinj.
}

2 Selvaggio's (1994) sample is composed of 47 carcasses out of which only 4 are medium-sized animals. Of these, only two were used in the three-patterned experiments. One experiment consisted of six bones and the other consisted of only one bone. The estimates for carcasses of sizes 3-4 are, thus, statistically meaningless. 
et al. (2012) admit that hominins may have gained access to carcasses before they were completely defleshed by felids. As documented by Bunn and Kroll (1986, Table 4), however, the number of larger mammal (sizes 3-4) humeral and femoral shaft specimens and the percentages of cut-marked specimens are almost identical for larger humerus (8 of $45,17.8 \%$ ) and femur ( 7 of $41,17.1 \%$ ) shaft specimens at FLK Zinj. They also mistakenly assume that the frequency of defleshing cut marks on humeri and femora should be equal to indicate equal access to fully-fleshed bones, even though actualistic, ethnoarchaeological data indicate otherwise (Bunn, 2001, Figs. 10.1 and 10.2). There are more individual cut marks on humeral than femoral shafts from FLK Zinj, a pattern that also occurs on fully fleshed humeri and femora defleshed by Hadza foragers. The strengths of muscle attachments on the humerus and femur are different, and the femur is longitudinally straighter than the humerus, which reduces the likelihood of mistakenly hitting the femur with the knife when it is obscured by muscle meat, hence lowering the frequency of femur cut marks.

Moreover, Pante et al.'s (2012) new interpretation is contradicted by their previous interpretations of tooth mark frequencies at the site, because, according to these, hominins had access mainly to defleshed carcasses (Selvaggio, 1994, 1998b). Only access to carnivore-defleshed carcasses would explain the high frequency of tooth marks on mid-shaft specimens. In contrast with this, if hominins had access to substantially more fleshed carcasses, as suggested by cut marks, this would yield a lower frequency of tooth marks, because carnivores would have had little reason to gnaw limb shafts that had already been defleshed and broken for marrow by hominins. The two interpretations are therefore incompatible.

In sum, for specific carcass sizes (e.g., sizes 3-4) and if considering percussion marks, Pante et al. (2012) provide support for hominins gaining access to bones after vultures. If considering tooth marks, they argue that hominins scavenged defleshed carcasses from felid kills, though none of their experimental set involves carcass processing from felids. ${ }^{3}$ If taking cut marks into account, they admit that hominins were obtaining substantially fleshed carcasses from leopard kills or undefined "carnivores". These interpretations are contradictory, and none is taphonomically well supported.

The problem with this mix of contradictions and interpretations is that Pante et al. (2012) - as with Blumenschine (1995), Capaldo (1997,1998b) and Selvaggio (1994,1998b) - never interpreted the three types of bone surface modifications (percussion, cut, and tooth marks) together without showing any contradiction. This should be done by observing the frequencies of the three types of marks jointly in each experiment carried out. The independent use of tooth and butchery mark frequencies does not resolve this problem, because it does not quantify the types of marks on each specimen and is not inclusive of the larger remainder of the sample bearing only one type of mark. Their interpretations have been based on partial use of bone surface information, because each type of mark has been treated separately, and more emphasis has been put on tooth marks than on hominin-imparted marks.

Furthermore, this debate is only sustainable there are indeed high frequencies of tooth marks at FLK Zinj, which has been questioned by Domínguez-Rodrigo and Barba (2006) and Domínguez-Rodrigo et al. (2007a). Pante et al. (2012), citing

\footnotetext{
3 This is conceptually important. Domínguez-Rodrigo (2009) argued that Blumenschine's Carnivore-only model involves mainly carcasses tooth-marked by hyenas and Selvaggio's (1994, 1998b) carnivore-to-hominin-to-carnivore model was artificially created by combining tooth mark frequency from durophagous carnivores (which create the highest tooth mark frequencies) and strict flesh-eating carnivores (e.g., felids) whose tooth-marked frequencies on hammerstone-broken assemblages are very low (Domínguez-Rodrigo et al., 2007a).
}

Blumenschine and Pobiner (2006: 402), dismiss these critiques as "unsubstantiated due to general methodological flaws that have yet to be remedied", an issue already addressed in detail by Domínguez-Rodrigo and Barba (2007). This controversy can only be overcome when more researchers from different backgrounds and academic traditions analyze the bones and provide further input.

Within this discussion, our present work is methodological and intends to address the following questions:

1. What model category (carnivore-first or hominin-first) provides the greatest heuristic value when considering cut, percussion, and tooth marks simultaneously in the interpretation of the FLK Zinj archaeofaunal assemblage?

2. What experimental background can be provided to model access to partially-fleshed carcasses, as suggested by Pante et al. (2012)? What frequencies of cut, percussion, and tooth marks does such a model create?

3. Can passive scavenging be defended using this or other experimental models?

To answer these questions, proper analogs must be used. The three-patterned models of hominins scavenging from felid kills have never been properly experimentally modeled (Domínguez-Rodrigo, 2009). Blumenschine's (1988) carnivore-only model is based on hyenid modification of bones. Capaldo's (1997, 1998b) hammerstone-to-carnivore and whole-bone-to-carnivore models are also based mainly on hyena modification. Selvaggio's (1994) carnivore-to-hominid-to-carnivore model is a mixture of several carnivores where the specific action of felids cannot be differentiated. Pobiner (2007) never experimentally modeled lion consumption of carcasses followed by human processing. The theoretical carnivore-hominid-carnivore model, as described by Pante et al. (2012) for interpreting carcass acquisition at FLK Zinj, should be less ambiguously named the felid-hominin-hyenid model. Blumenschine (1986) documented that the only carnivore-first scavenging niche for hominins would have been access to carcasses after felids, not after canids or hyenids. None of Blumenschine and colleagues' models strictly reproduces felids defleshing carcasses, followed by hominin removal of flesh scraps and marrow extraction and hyenas consuming the post-depositionally discarded grease from long bone ends. This sequence of taphonomic behaviors has only been experimentally modeled by Domínguez-Rodrigo (1997a, 1997b) and, more recently, by Gidna et al. (2013). These and Pante et al.'s (2012) models involving the production of tooth, percussion, and cut marks will be used in the present work. The results provide a more heuristic interpretation of hominin and carnivore interaction in the FLK Zinj assemblage than any other previous model.

\section{Sample and method}

\subsection{Research question 1: carcass access type by hominins at FLK Zinj}

In the present study, large carcasses [Bunn's (19822) carcass size groups 3 and 4] will be used to address the reconstruction of hominin carcass acquisition at FLK Zinj because medium-sized carcasses are the most represented at the site. Smaller carcasses are not included because no felid-hominin-hyenid experimental model exists which is adequate for this carcass size, which would involve either leopard or cheetahs as primary felid consumers.

The following experimental sets have been used (Table 1):

1. Model: Felid-hominin (F-H). This model was implemented for 12 carcasses (ten size 3 and two size 4 ) hunted and defleshed by lions in Tarangire National Park (Tanzania). Carcasses were then 
processed with the aid of stone tools to replicate scenarios of hominins having secondary access to felid-defleshed carcasses and removing the available flesh scraps and bone marrow. See details of the sample and method in Gidna et al. (2013). Carcasses were not exposed to subsequent modification by bonecrunching carnivores.

2. Model: Felid-hominin-hyenid $(\mathrm{F}-\mathrm{H}-\mathrm{H})$. Four carcasses from Maasai Mara, Galana and Kulalu (Kenya) defleshed by lions, subsequently processed with stone tools to remove flesh scraps and long bone marrow and then exposed to the action of bonecrunching hyenas were used for this model. Details of the sample and butchering method can be found in DomínguezRodrigo (1997b).

3. Model: Hominin-carnivore $(\mathrm{H}-\mathrm{C})$. Three medium-sized [Bunn's (1982) size 3] carcasses were butchered with stone tools and then exposed to hyenas and other carnivores (see details in Domínguez-Rodrigo, 1997b). The mean values for each type of mark of Pante et al.'s H-C model were also added to this model to increase sample size.

Table 1

Sources of data used for multivariate analyses (Figs. 1 and 2) for cut marked specimens obtained for three models $(\mathrm{H}-\mathrm{C}, \mathrm{F}-\mathrm{H}-\mathrm{H}, \mathrm{F}-\mathrm{H})$.

\begin{tabular}{|c|c|}
\hline & References \\
\hline \multicolumn{2}{|c|}{ Primary access (butchery of complete carcasses: $\mathrm{H}-\mathrm{C}$ model) } \\
\hline $\mathrm{H} 1 \mathrm{~S} 1 / 2 \mathrm{a}$ & Domínguez-Rodrigo (1997b) \\
\hline $\mathrm{H} 1 \mathrm{~S} 1 / 2 \mathrm{~b}$ & Domínguez-Rodrigo (1997b) \\
\hline $\mathrm{H} 1 \mathrm{~S} 1 / 2 \mathrm{~d}$ & Domínguez-Rodrigo (1997b) \\
\hline Cow & Gidna et al. (2013) \\
\hline Buffalo & Gidna et al. (2013) \\
\hline Sizes 3-4 mean values & Pante et al. (2012) \\
\hline \multicolumn{2}{|c|}{$\begin{array}{l}\text { Secondary access (butchery of defleshed carcasses from felid kills: } \mathbf{F}-\mathbf{H}-\mathbf{H} \\
\text { model) }\end{array}$} \\
\hline $\mathrm{H} 2 \mathrm{~S} 1 / 2 / 3 \mathrm{a}$ & Domínguez-Rodrigo (1997a,b) \\
\hline $\mathrm{H} 2 \mathrm{~S} 1 / 2 / 3 \mathrm{~b}$ & Domínguez-Rodrigo (1997a,b) \\
\hline $\mathrm{H} 2 \mathrm{~S} 1 / 2 / 3 \mathrm{c}$ & Domínguez-Rodrigo (1997a,b) \\
\hline $\mathrm{H} 2 \mathrm{~S} 1 / 2 / 3 \mathrm{~d}$ & Domínguez-Rodrigo (1997a,b) \\
\hline \multicolumn{2}{|c|}{ Secondary access (butchery of carcasses from felid kills: F-H model) } \\
\hline 12 carcasses & Gidna et al. (2013) \\
\hline
\end{tabular}

These experimental models were compared against the $\mathrm{V}-\mathrm{H}-\mathrm{C}$ model and the data from the FLK Zinj archaeofaunal assemblage. For the latter, two data sets were used separately: those reported by Blumenschine (1995) for all types of marks, and those reported by Domínguez-Rodrigo et al. (2007a) for the same types. To compare with the Pante et al. (2012) results, Blumenschine's (1995) bone portion method was used. Marks were reported for all bone portions together and for mid-shafts (cut and tooth marks) or for midshafts alone (percussion marks), because strong colinearity (i.e., positive correlation between variables) was documented when using all bone portions and mid-shafts for percussion marks. The amount of variance explained increased slightly when discarding the variable of percussion mark frequencies on all bone portions, given its irrelevance to discriminating experimental samples.

A multiple discriminant analysis (MDA) was used to differentiate among the different experimental groups and classify the FLK Zinj data adequately. Whereas PCA (Principal component analysis) maximizes sample variance, MDA maximizes intergroup variance, which allows factor discrimination. There is some debate regarding the effects of using samples with normal or non-normal distributions and heteroscedastic versus homoscedastic variance in PCA (Hair et al., 1998). For linear discriminant analysis this is mandatory, however. For this reason, all of the numeric variables were inspected for skewness and normality. Shapiro-Wilk and Anderson-Darling normality tests were used. The kurtosis and skewness of data were measured using the "fBasics" library of R. The "nortest" library of $\mathrm{R}$ was used to perform normality tests. Two analytical approaches were used for MDA. The first one involved the use of the "lda" function of the MASS library. This is the typical linear discriminant analysis (LDA), resulting from a linear combination of variables with respect to the discriminant coefficients. Some of the downsides of linear discriminant analysis are the inadequate definition of group division boundaries and its lack of flexibility. Furthermore, when too many correlated predictors exist, LDA has to simultaneously manipulate many parameters with high variance. A mixture discriminant analysis (MXDA) allows mixing heterogeneous distributions in the same model. It is argued to outperform linear discriminant analyses (LDA) and quadratic discriminant analysis (QDA; Hastie and Tibshirani, 1996; Ma and He, 2008). For these reasons, MXDA introduces the flexibility of nonlinear regression models by allowing the use of nonnormal distributions and heteroscedastic samples. When they are compared simultaneously, it has been shown that LDA was suboptimal in situations of skewed predictors and that MXDA performed significantly better (Rausch and Kelly, 2009). Given that in our analytical samples the variables did not adapt to a linear normal distribution, this may have introduced some noise in the results obtained by MDA. For this reason, and as a confirmatory test, we also used a MXDA in the classification of the data sets and the selection of discriminant variables. This was done by using the "mda" library of R.

Prior to performing the discriminant analyses, data were bootstrapped. Bootstrap estimates are empirically superior over traditional methods when sample size is small, provided that the original sample is truly representative of a population. Bootstrap discriminant analyses have been shown to be mathematically more accurate than standard discriminant methods (Chernick, 1999). Bootstrap samples do not have to follow Gaussian distributions and this is something that allows a confident use of MDA tests in the present study. Estimators that have a large bias are a potential problem for MDA. By using bootstrap estimators, the error rate in MDA is decreased drastically, because it provides a bias correction that traditional methods do not have (Chernick, 1999).

Although the adequate number of bootstrap replications to be used has been suggested to be smaller than 1000 (Booth and Sarkar, 1998), researchers often use larger numbers (e.g., 10,000) thinking that the larger the number of replications, the better the accuracy of the central measure estimator and its error bias. This is incorrect. Hall's (1992) uniform resampling procedure suggested a step-wise approach to bootstrapping, starting with low replications and increasing until error bias was basically similar in successive replications. We followed this approach. We obtained error bias stabilization before reaching 1000 replications. However, we performed as many as 5000 replications to confirm minimum error bias, as suggested by Chernick (1999), since computers allow generating $>1000$ iterations at no cost. Using 10,000 replications, as is commonly practiced, was thus unnecessary. Bootstrapped samples were then analyzed through MDA and MXDA tests.

\subsection{Research question 2: were hominins acquiring partially defleshed carcasses?}

For this research question we proceeded differently. Pante et al (2012) suggest that hominins had more frequent access to fleshed humeri than femora, based on the higher frequency of cut marks on humeri, and that femora might have been defleshed by carnivores (namely, felids). If hominins had access to fleshed humeri, this according to Blumenschine's (1986) carnivore carcass consumption sequence - implies substantially early to intermediate access, because after evisceration, carnivores deflesh the hindquarters and then consume meat on both limbs, starting on upper limb bones and finishing with lower limb bones. The best way to test Pante 
et al.'s (2012) hypothesis would be through confrontational scavenging with lions. Given the lack of such an analog, we constructed an artificial analog by combining cut mark frequencies of humeri as documented in the $\mathrm{H}-\mathrm{C}$ model and cut mark frequencies of femora as experimentally documented in $\mathrm{F}-\mathrm{H}$ or $\mathrm{F}-\mathrm{H}-\mathrm{H}$ models. Given that bootstrap procedures are only powerful when the sample size from which resampling takes place is larger than 10 (Chernick, 1999), we decided to exclude data from Domínguez-Rodrigo's (1997a,b) H-C experimental sample $(n=4)$. Since a large sample size was required for the primary access hypothesis (full exploitation of carcasses by hominins followed by scavenging carnivores), but is experimentally unavailable, we decided to use recent (Upper Pleistocene) archaeofaunal assemblages where taphonomic studies have shown an anthropogenic origin of the accumulation and for which evidence exists that hominins had primary access (Table 2). Although conceptually this provides less heuristic power than using experimentally controlled samples, they constitute the best proxy for a large sample from which bootstrap resampling can be meaningful. For this purpose, 35 assemblages of medium-sized cervid and equid remains have been used (Table 2).

Table 2

A selection of Iberian Upper Pleistocene sites where data for cut mark frequencies for humeri and femora from medium-sized carcasses (cervids and equids) has been documented separately.

\begin{tabular}{|c|c|c|}
\hline Site and level & $\begin{array}{l}\text { Chronology-cultural } \\
\text { period }\end{array}$ & Reference \\
\hline Ambrosio & Solutrean (middle) & Yravedra $(2005,2007)$ \\
\hline Ambrosio & Solutrean (upper) & Yravedra $(2005,2007)$ \\
\hline Estebanvela 1 & Magdalenian & Yravedra $(2005,2006)$ \\
\hline Estebanvela 2 & Magdalenian & Yravedra $(2005,2006)$ \\
\hline Estebanvela 3 & Magdalenian & Yravedra $(2005,2006)$ \\
\hline Amalda VII & Mousterian & Yravedra $(2005,2010)$ \\
\hline Amalda VI-V & Gravettian & Yravedra (2010) \\
\hline Esquilleu XIF & Mousterian & Yravedra (2005) \\
\hline Esquilleu XIII & Mousterian & Yravedra (2005) \\
\hline Esquilleu VI & Mousterian & Yravedra (2005) \\
\hline Cofresnedo & Aurignacian & Yravedra (in progress) \\
\hline Coimbre & Magdalenian & Yravedra (in progress) \\
\hline Cobalejos b & Aurignacian & Yravedra (2013) \\
\hline Cobalejos c & Aurignacian & Yravedra (2013) \\
\hline Cobalejos d & Mousterian & Yravedra (2013) \\
\hline Cobalejos e & Mousterian & Yravedra (2013) \\
\hline Cobalejos h & Mousterian & Yravedra (2013) \\
\hline Cobalejos i & Mousterian & Yravedra (2013) \\
\hline Cobalejos j & Mousterian & Yravedra (2013) \\
\hline Cobalejos K & Mousterian & Yravedra (2013) \\
\hline Cuco & Gravettian & Yravedra (in progress) \\
\hline Ruso III & Solutrean & Yravedra et al. (2010) \\
\hline Ruso iV b & Aurignacian & Yravedra et al. (2010) \\
\hline Morín 4 Grav & Gravettian & $\begin{array}{l}\text { Yravedra and } \\
\text { Gómez-Castanedo (2010a) }\end{array}$ \\
\hline Morín 5a Grav & Gravettian & $\begin{array}{l}\text { Yravedra and } \\
\text { Gómez-Castanedo (2010a) }\end{array}$ \\
\hline Morín 15 & Mousterian & $\begin{array}{l}\text { Yravedra and } \\
\text { Gómez-Castanedo (2010a) }\end{array}$ \\
\hline Otero 4 & Aurignacian & $\begin{array}{l}\text { Yravedra and } \\
\text { Gómez-Castanedo (2010b) }\end{array}$ \\
\hline Gabasa $a-c$ & Mousterian & Blasco (1995) \\
\hline Gabasa d & Mousterian & Blasco (1995) \\
\hline Gabasa e & Mousterian & Blasco (1995) \\
\hline Gabasa f & Mousterian & Blasco (1995) \\
\hline Gabasa g & Mousterian & Blasco (1995) \\
\hline Gabasa h & Mousterian & Blasco (1995) \\
\hline La Fragua 4 & Magdalenian & Marín-Arroyo (2004) \\
\hline Higueral de Motillas & Magdalenian & Cáceres and Anconetani (1997) \\
\hline
\end{tabular}

Data for the secondary access hypothesis were gathered from Domínguez-Rodrigo's (1997b) F-H-H sample $(n=4)$ and from Gidna et al.'s (2013) sample of medium-sized and large carcasses processed with stone tools after lion consumption $(n=11)$. Data were tallied according to element (humerus and femur).

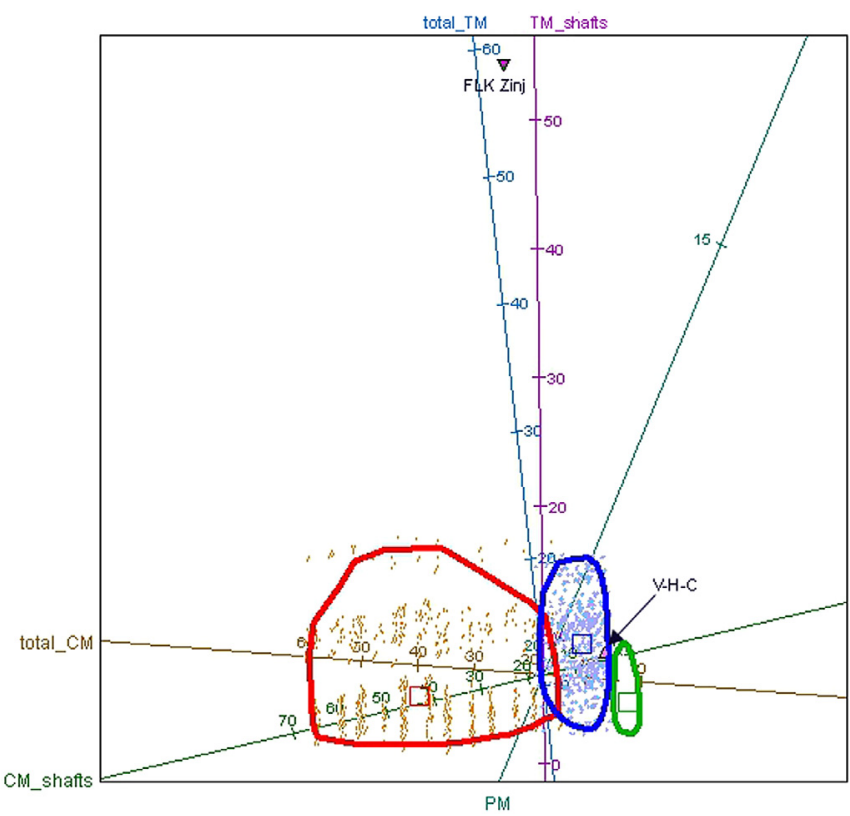

Fig. 1. Multiple discriminant analysis (using a canonical variate approach) on a bootstrapped sample of experimental sets: primary access to completely fleshed carcasses butchered with stone tools reproducing the $\mathrm{H}-\mathrm{C}$ model (large red alpha bag to the left), secondary access to variously defleshed carcasses in the $\mathrm{F}-\mathrm{H}-\mathrm{H}$ model (mediumsized blue alpha bag), and secondary access to defleshed carcasses from the F-H model (small green alpha bag to the right). Centroid location within each alpha bag is also shown (squares). Cut marks appear as the most discriminant variables. Location of FLK Zinj outside the experimental sets is caused by the use of the high estimates of tooth marks made by Pante et al. (2012). (For interpretation of the references to colour in this figure legend, the reader is referred to the web version of this article.)

Non-parametric Wilcoxon (Mann-Whitney) tests were applied to test the null hypothesis of humeri and femora being equally cutmarked when processing fully-fleshed carcasses. Data were analyzed using bootstrapping procedures. Randomized bootstrap methods were preferred over permutation approaches because it was assumed, after examining the raw data, that differences of tooth mark types on cancellous and dense bone could be representative of different populations. Therefore, a non-parametric bootstrapping approach using an alternative model was carried out. Data were randomly resampled 1000 times, because given the characteristics of the data (see above), that number of replicates maximized accuracy in prediction of mean differences, standard error of mean difference, and power (Pattengale et al., 2010). Mean values were established within adjusted bootstrap intervals using a biascorrected-and-accelerated $\left(\mathrm{BC}_{\mathrm{a}}\right)$ method (Efron, 1987). $\mathrm{BC}_{\mathrm{a}}$ tends to produce good interval limits that are more adjusted than typical studentized interval estimates (Zieffler et al., 2011). For the significance of the differences, both bootstrapped $T$ tests were carried out and Cohen's $\delta$ values were obtained. Cohen's $\delta$ provides a value from 0 to 1 in which the mean difference is considered of small effect $(\delta \leq 0.2)$, medium effect $(\delta=0.2-0.7)$, and large effect $(\delta \geq 0.8)$. All computations were made with the bootstrap functions of the "boot" R library.

\section{Results}

3.1. Testing access to carcasses by multivariate use of tooth, percussion, and cut marks

MDA and MXDA tests on bone surface modifications from FLK Zinj yielded similar results (Table 3 ). The MDA test produced a twodimension solution which accounted for $96 \%$ of the sample 
variance. The first factor explained $93 \%$ of the total variance alone. This result showed a very successful discriminant test. In fact, the classification error was very low: $93.4 \%$ of the sample cases were correctly classified. The MDA showed that not all mark types have the same discriminant weight. Factor 1 was determined by two variables: cut mark frequencies on shafts and cut mark frequencies on all bone portions. These clearly separated experimental sets (Fig. 1). Tooth mark frequencies showed the least impact on factor 1 (Fig. 1), but they accounted for most variance in factor 2 (although contributing only $3 \%$ of sample variance). These results were reproduced by MXDA (Table 3) with some modifications. The MXDA produced a two-dimension solution that explained $92.49 \%$ of sample variance (factor 1 accounted for $77.33 \%$ of the variance). The success of classification reached $97.2 \%$ of points correctly classified. MXDA granted substantially more discriminant power to the frequencies of cut marks on shafts than on all bone portions. The results for the second factor are different from those provided by the MDA. In this case, percussion marks are more relevant, given the wider range of variability than tooth marks. Tooth marks are the least discriminatory of all the bone surface modification types, given that primary access by felids to bones generates similar frequencies of tooth marks as scavenging carnivores having access to hominin-discarded bones (Domínguez-Rodrigo et al., 2007b).

Table 3

Discriminant coefficient scores for the first two functions of the MDA and MXDA tests. CM, cut marks; PM, percussion marks; TM, tooth marks.

\begin{tabular}{llllll}
\hline & \multicolumn{2}{l}{ MDA } & & \multicolumn{2}{l}{ MXDA } \\
\cline { 2 - 3 } \cline { 5 - 6 } \cline { 5 - 6 } & Function 1 & Function 2 & & Function 1 & Function 2 \\
\hline Total CM & 0.0858 & 0.0083 & & 0.0650 & 0.0030 \\
CM on shafts & 0.0493 & 0.0125 & & 0.1579 & 0.0039 \\
PM & 0.0079 & 0.0198 & & 0.0073 & 0.3573 \\
Total TM & 0.0133 & 0.1118 & & 0.0075 & 0.0019 \\
TM on shafts & 0.0002 & 0.2030 & & 0.0038 & 0.0003 \\
\hline
\end{tabular}

The mean values of the $\mathrm{V}-\mathrm{H}-\mathrm{C}$ model fall almost in between the $\mathrm{F}-\mathrm{H}$ and $\mathrm{F}-\mathrm{H}-\mathrm{H}$ models; that is, its taphonomic signature places it with the scavenging models (Fig. 1). The outlier in this analysis is the high frequency of tooth marks at FLK Zinj reported by Blumenschine (1995) and Pante et al. (2012), which is not reproduced by any of the experimental models where the primary consumer (i.e., type of carnivore) is known. It certainly does not correspond with a model where carcasses are initially consumed by felids. One could argue that the palimpsest nature of the assemblage may contain carcasses processed only by hominins and others exclusively consumed by carnivores, but in order to generate the high frequency of tooth marks reported for FLK Zinj, a large portion of the long bones should have been broken by carnivores, a scenario which is contradicted by the percussion mark data. These show that all or virtually all long bones were broken by hominins. This contradiction can be explained by misidentification of tooth marks by Blumenschine (1995) in the FLK Zinj assemblage, as suggested by DomínguezRodrigo and Barba (2006, 2007). If we replace the bone surface modification information on the FLK Zinj assemblage provided by Pante et al. (2012) with that reported by Domínguez-Rodrigo et al. (2007a), a different situation can be observed (Fig. 2). In this case, the FLK assemblage plots within the same space as the experimental models and appears within the $95 \%$ confidence alpha bag of the $\mathrm{H}-\mathrm{C}$ model and, therefore, suggests primary access to fleshed carcasses.

The effect of the original sample prior to bootstrapping should be emphasized. Figs. 1 and 2 show that the smallest alpha bag is the one representing the largest original sample for which bootstrapping has corrected the error bias. The other models $(\mathrm{H}-\mathrm{C}$ and $\mathrm{F}-\mathrm{H}-\mathrm{H}$ ) not only were almost one-third smaller, but were also

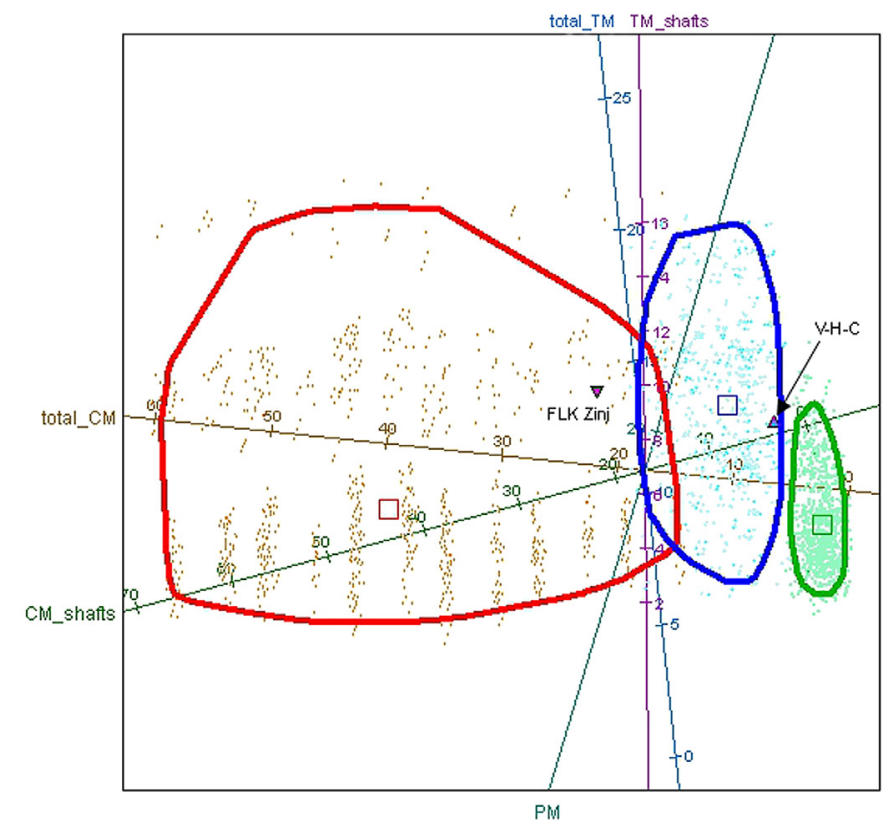

Fig. 2. Multiple discriminant analysis (using a canonical variate approach) on a bootstrapped sample of experimental sets: primary access to completely fleshed carcasses butchered with stone tools reproducing the $\mathrm{H}-\mathrm{C}$ model (large red alpha bag to the left), secondary access to variously defleshed carcasses in the $\mathrm{F}-\mathrm{H}-\mathrm{H}$ model (medium-sized blue alpha bag), and secondary access to defleshed carcasses from the $\mathrm{F}-\mathrm{H}$ model (small green alpha bag to the right). Centroid location within each alpha bag is also shown (squares). Cut marks appear as the most discriminant variables. In contrast with Fig. 1, location of FLK Zinj inside the experimental sets is caused by the use of the tooth mark estimates documented by Domínguez-Rodrigo and Barba (2006) in this assemblage. Notice how the combination of the three mark types show that FLK Zinj represents an assemblage of carcasses butchered by hominins after having primary access to them and where bulk defleshing instead of intensive flesh scrap removal was targeted (see text). (For interpretation of the references to colour in this figure legend, the reader is referred to the web version of this article.)

more diverse, given that they included experiments reproducing intensive butchery of even the smallest flesh scraps (which is more likely to generate more cut marks) and standard butchery aimed at flesh bulk removal (leaving fewer marks) (Domínguez-Rodrigo, 1997a). The first type of experiment is responsible for the left elongation of the $\mathrm{H}-\mathrm{C}$ alpha bag, whereas the latter account for the right elongation thereof. The position of the FLK Zinj assemblage in the right side of the $\mathrm{H}-\mathrm{C}$ alpha bag shows that hominins at Zinj did not target flesh scrap removal but bulk flesh processing. The larger alpha bag of the $\mathrm{F}-\mathrm{H}-\mathrm{H}$ model compared to that of the $\mathrm{F}-\mathrm{H}$ model is also understandable because it included not just defleshed carcasses, but also a partially fleshed one (Domínguez-Rodrigo, 1997a). The $\mathrm{F}-\mathrm{H}$ alpha bag is, therefore, probably more representative of the common way lions consume carcasses and how hominins impact bones with secondary access to them. If hominins were acquiring partially fleshed carcasses, as Pante et al. (2012) suggest, the FLK Zinj archaeofaunal assemblage should occur to the right or left of the $\mathrm{F}-\mathrm{H}-\mathrm{H}$ alpha bag according to how fleshed or defleshed carcasses were when they found them. This can be confirmed by the position of the mean values for the $\mathrm{V}-\mathrm{H}-\mathrm{C}$ model, in which vultures defleshed carcasses thoroughly, and its location to the right of the $\mathrm{F}-\mathrm{H}-\mathrm{H}$ alpha bag and overlapping with several points of the $\mathrm{F}-\mathrm{H}$ model, is more typical of felid consumption of carcasses.

\subsection{Testing the "access to only partially defleshed carcasses hypothesis"}

Pante et al. (2012) provide contrasting estimates of cut-marked humeri and femora at FLK Zinj by under-identifying cut marked 
femora ( $n=3 ; 12.5 \%)$. Although no specific carcass size is provided, if this estimate refers to all carcass sizes, it seriously underestimates the actual number of cut-marked specimens at the site. For medium-sized carcasses alone, Domínguez-Rodrigo et al. (2007a) identified 6 cut-marked specimens (14.6\%), Bunn and Kroll (1986) identified 11 cut-marked specimens (21.1\%) and Oliver (1994) identified 10 cut-marked specimens $(24.4 \%$ in Oliver's tallied sample). Domínguez-Rodrigo et al. (2007a) claimed that their identification was very conservative and that several ambiguous cut marks were not included in their study, so some estimates by Bunn and Kroll (1986) and Oliver (1994) are probably closer to the original cut mark frequency at the site.

Regardless of this, when comparing humeri and femora in experiments reproducing complete defleshing of carcasses with stone tools, femora regularly appear less cut-marked than humeri (Domínguez-Rodrigo, 1997a,b). As already noted, this same pattern is also produced ethnographically by Hadza butchers using steel knives (Bunn, 2001). This also applies to the sample of Upper Pleistocene sites analyzed in the present work (Fig. 3), where frequencies of cut-marked bone are higher for humeri compared to femora. A Mann-Whitney-Wilcoxon test shows that both sets differ significantly when using bootstrapped samples ( $W=605,943, p=0.000$ ). A bootstrap interval, following the bootstrap bias-corrected-and accelerated method $\left(\mathrm{BC}_{\mathrm{a}}\right)$ shows a mean difference between the cut-marked humeral and femoral fragments of $1.4 \pm 0.8$ if using the Paleolithic collection (Tables 2 and 4). Cohen's $\delta$ value is 0.17 , which shows a small effect size. These statistical tests falsify Pante et al.'s (2012) assertion that fewer cut-marked femoral specimens compared to cut-marked humeral fragments is indicative of carnivore defleshing of hindquarters. The morphology of the humerus and femur, as well as the ergonomics during butchery and the differential muscle attachments in both bones, probably account for the more frequent cutmarking on humeri than femora when defleshing complete carcasses (Table 4).

Table 4

Mean and 95\% confidence intervals of bootstrapped samples for humerus and femur from secondary access experiments and data from Upper Pleistocene sites (Table 3).

\begin{tabular}{|c|c|c|c|c|c|}
\hline & \multicolumn{2}{|c|}{$\begin{array}{l}\text { Secondary access } \\
\left(\mathrm{MDR}^{\mathrm{a}}\right)\end{array}$} & \multicolumn{2}{|c|}{$\begin{array}{l}\text { Upper Pleistocene } \\
\text { sites }^{\text {b }}\end{array}$} & \multirow{2}{*}{$\begin{array}{l}\text { FLK Zinj } \\
(\text { sizes 3-4) } \\
\text { Humerus }\end{array}$} \\
\hline & Humerus & Femur & Humerus & Femur & \\
\hline $\begin{array}{l}n \text { (prior to } \\
\text { bootstrap) }\end{array}$ & 15 & 15 & 35 & 35 & $18 / 57(20.5)$ \\
\hline Mean & 1.01 & 1.87 & 21.07 & 20.43 & - \\
\hline s.d. & 2.38 & 2.92 & 13.25 & 14.73 & - \\
\hline 95\% c.i. & $0.85-1.14$ & $1.69-2.05$ & $20.23-21.91$ & $19.52-21.35$ & \\
\hline
\end{tabular}

*** Data from Table 2.

a Data from Domínguez-Rodrigo (1997b).

b Data from Domínguez-Rodrigo et al. (2007a).

Access to carcasses when humeri were fleshed and femora were defleshed would show high percentages of cut-marked humeri and very low percentages of femoral cut-marked fragments. Instead, the FLK Zinj cut-marked sample shows that humeri are cut-marked as much as humeri from Upper Pleistocene sites and femora are slightly less cut-marked than femora from Upper Pleistocene sites if considering the bootstrapped sample but similarly if considering the $95 \%$ confidence interval range of the non-bootstrapped sample. The FLK Zinj femoral data also differ drastically from the less cutmarked femora from carcasses where this anatomical section has previously been defleshed by carnivores, both when comparing it to the bootstrapped and non-bootstrapped samples (Fig. 3). These results do not support access to partially-defleshed hindlimbs and add further support to the primary access hypothesis.

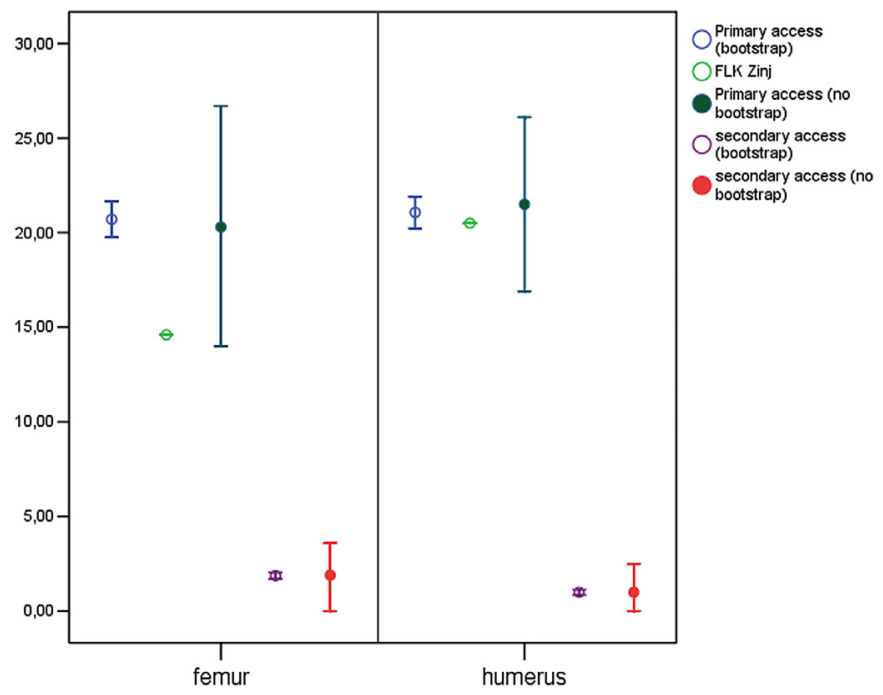

Fig. 3. Data of frequencies of cut-marked femoral and humeral fragments at FLK Zinj compared to samples representing primary access to fleshed carcasses (Table 2) and experimental samples reproducing secondary access to scavenged carcasses from felid kills. Both samples show their ranges of variation (95\% confidence intervals) using raw data and the modified bootstrapped data. Notice how both humerus and femur fall within the range of variation of the primary access sample and well outside the ranges of variation of bootstrapped and non-bootstrapped data of experiments replicating secondary access to carcasses. This refutes the claim by Pante et al. (2012) that femora were defleshed before hominins had access to them.

\section{Discussion}

It has been argued that Early Pleistocene hominins at FLK Zinj might have obtained carcasses by passive scavenging of defleshed remains from felid kills (Blumenschine, 1986, 1995) and somewhat more fleshed remains from tree-stored leopard kills (Capaldo, 1995; Cavallo, 1998). Some researchers view the hunting-scavenging debate with skepticism, suggesting that both sides have equally well-supported arguments. However, a growing body of research literature over the past 15 years has provided enough evidence to show that the two hypotheses have fairly different heuristics: that is, several arguments have questioned the passive scavenging hypothesis as it was initially described, showing a number of inconsistencies, and have provided strong arguments in favor of the primary access hypothesis. Several of these arguments have not been addressed by the partisans of passive scavenging, rather being satisfied by suggesting that such a hypothesis still is an alternative to that of primary access (Blumenschine and Pobiner, 2006; Pante et al., 2012). Recently Pante et al. (2012) acknowledged that carcasses were substantially fleshed when acquired by hominins. We argue that to retain any credibility, the hypothesis of passive scavenging has to overcome the following falsifying arguments:

\subsection{Tooth marks and felid kills}

1. Passive scavenging from carnivores, as currently conceived, should be modeled in the following terms: felids were the primary consumers of carcasses, exploiting most of the flesh from them; hominins followed them by focusing mostly on marrow extraction, and hyenas intervened lastly by deleting greasebearing bones. From a conceptual point of view, all of the Carnivore-only experiments carried out by Blumenschine (1988) that inspired the Carnivore-Hominin-Carnivore model (Selvaggio, 1994; Blumenschine, 1995) were carried out by using hyenas as carnivores (Blumenschine, 1995; Capaldo, 1995) or a mix of carnivores including felids, hyenids and canids, and 
tallying the resulting tooth mark frequencies together when comparing them to FLK Zinj (Selvaggio, 1994). Bone-crunching carnivores (hyenas) are a bad proxy for flesh-eaters (felids), because they modify bones differently. If felids and their resultant bone damage are actually used as the "first" carnivore in multiple-pattern models (as they ought to be, according to the hypothetical scenario constructed by the proponents of these models), instead of hyenas, then tooth mark percentages drop drastically (especially on mid-shafts) and become nondiagnostic (Domínguez-Rodrigo et al., 2007b).

2. Blumenschine and Pobiner (2006) have argued that the frequency of tooth marks documented at FLK Zinj (intermediate between Carnivore-only and Hammerstone-carnivore models) can be explained by felids initially defleshing carcasses as is experimentally modeled by Selvaggio (1994). It has been argued that about 65\% of mid-shafts in Selvaggio's Carnivore-Hominid experiments are tooth marked (Blumenschine and Pobiner, 2006). However, this is misleading. The bulk of Selvaggio's experiments are based on small carcasses, more easily fragmented by felids than the larger carcasses represented at FLK Zinj. The high frequency cited by Blumenschine and Pobiner (2006) is derived by lumping together broken bone fragments and complete bones. Broken fragments are more highly tooth-marked than complete bones, and a hominin would pay no attention to them because they would be resource-free. In addition, the Carnivore-Hominin-carnivore experimental sample is obtained by lumping together all carnivore types (bone crunching and flesh eaters) and not just felids. The percentage thus obtained does not reflect the basic premises of the CarnivoreHominin-Carnivore scenario (Selvaggio, 1994; Blumenschine, 1995; Capaldo, 1995), according to which hominids were scavenging complete (marrow-bearing) long limb bones (ignoring the fragmented ones with no marrow) from felid kills. However, Selvaggio (1994) quantified tooth mark densities (number of marks per bone specimen) in experimental assemblages and showed how distinct tooth mark frequencies generated by felids on complete bones are from those inflicted by hyenas. For felidderived assemblages, $75 \%$ of the specimens have tooth mark densities <21 (Selvaggio, 1994). More specifically, up to $96 \%$ of small animal bone assemblages displayed tooth mark densities $\leq 20$, while $86 \%$ of medium animal bone assemblages displayed tooth mark densities $\geq 21$. These values are significantly lower than those of carnivore-only experimental assemblages, in which hyenas had been responsible for bone modifications and in which densities $>70$ were usually reported for both carcass sizes. These results clearly indicate that felids mark limb bones at much lower rates than hyenas. This contrast is even more acute when observing complete bones remaining unbroken by felids after carcass defleshing. For such specimens, 50\% displayed not a single tooth mark (Selvaggio, 1994).

In addition, Selvaggio's (1994) data indicate an intra-element difference between felids and hyenas in tooth mark distribution. Of all bone portions in the felid-modified sample, mid-shafts exhibited the lowest mean percent of specimens bearing at least one tooth mark. Frequencies are always $<50 \%$, much lower than those reported for hyena-created and exclusively hyena-modified assemblages. ${ }^{4}$ More specifically, in the felid sample the mean

\footnotetext{
4 Pobiner (2007) documents similar results. The comparability of her frequencies to those from the archaeological record is low, however, since she only used complete bones in her experiments instead of fragmented assemblages as in archaeological sites. By breaking her complete-bone sample into fragments, the tooth-mark frequencies would decrease significantly.
}

percent of mid-shafts bearing tooth marks is $21.7 \%$, and complete bone specimens bearing at least one tooth mark is $22.6 \%$ of the total sample. Again, these values are extremely low compared to those in assemblages created and modified exclusively by hyenas. The contrast is even more marked when one considers that part of the felid tooth mark sample was created by lions on the bones of small gazelles, far outside the larger body size of more "typical" lion prey (e.g., Schaller, 1972). This means that if hominins were acquiring the complete bones from this sample, they would be further reducing the frequency of tooth marks by breaking open the bones and generating multiple fragments. This is supported by recent studies by Domínguez-Rodrigo et al. (2007b) who show that tooth mark damage reported for mid-shafts from carcasses consumed by felids (cheetah, leopard and lion) and later broken by humans are $<15 \%$, is lower than in Hammerstone-carnivore scenarios where hyenas were used as secondary scavengers (see also Gidna et al., 2013).

This advises against using tooth mark distribution in complete elements as a proxy for hammerstone broken bones following similar processes of tooth-marking. Complete bones tooth-marked by felids will always show higher frequencies of tooth-marked specimens than broken elements.

3. If hominins were exploiting felid kills, they could have used the felid-transported carcasses at such loci as inferred from several Olduvai sites (Bunn et al., 2010; Domínguez-Rodrigo et al., 2010c) by exploiting the remaining flesh and marrow. The fact that a large number of complete bones survived, together with the lack of percussion traces (or cut marks) at most of the Olduvai sites falsifies the hypothesis that hominins were seeking felid kills, despite their repeated visits to those sites where felids were accumulating many carcasses and leaving unbroken dozens of long bones (Domínguez-Rodrigo et al., 2010c).

4. A study of tooth mark frequencies at FLK Zinj shows that the percentage previously identified by Blumenschine and colleagues is extremely inflated and results from misidentifying biochemical marks caused by fungi and bacteria in combination with root etching as carnivore-imparted tooth marks (Domínguez-Rodrigo and Barba, 2006, 2007). The actual frequency of tooth marks on mid-shafts from all carcasses at FLK Zinj is $<20 \%$, much lower than that of any of the Carnivore-first experimental models reproduced by Blumenschine (1988) or Selvaggio (1994). Blumenschine et al.'s (2007) arguments against his statement conflate the taphonomic signatures left by microscopic bioerosion caused by single hyphae of fungi with the macroscopic bioerosion caused by colonies of fungi associated with plant roots (Domínguez-Rodrigo and Barba, 2007).

\subsection{Cut marks}

1. Equifinality I. From a strictly analytical consideration, Domínguez-Rodrigo (2002) argued that the equifinality reported by Capaldo (1995) in the use of cut marks was merely methodological. Capaldo (1995, 1997, 1998b) claims that percentages and distributions of cut marks are indistinguishable in experimental scenarios reproducing early access (defleshing of carcasses) or secondary access (removal of flesh scraps from carnivore kills) to carcasses. The ranges of variation of both experimental samples overlap. Cut marks, thus, would be subjected to equifinality (Capaldo, 1995, 1997, 1998b). It is clear that this methodology of Blumenschine, Capaldo and Selvaggio is not suitable for the study of cut marks, because the analyses of bone sections per se could never test, for instance, Bunn and Kroll's (1986) hypothesis that cut marks are related to the amount of bulk flesh extracted from bones. Flesh is differentially 
distributed according to bone element. Similarly the small scraps of flesh that might survive carnivore consumption also show a typical pattern of anatomical distribution according to bone type and bone section. Analyses of cut marks per bone section cannot relate the amount of meat removed to the distribution and percentages of the resulting cut marks. Thus two different behaviors may mimic each other when analyzed by the method of Blumenschine, Selvaggio and Capaldo. The removal with cutting tools of skin and periosteum from lower limb bones of carnivore-defleshed carcasses may leave an abundance of cut marks on all the lower-limb sections (epiphyses, near-epiphyses and mid-shaft fragments). The total percentage and sectional distribution of cut marks per carcass will be similar to cases in which hominins processed fully fleshed upper limb bones and discarded the lower limb elements. The way to differentiate these two scenarios is by quantifying the cut marks by element (upper limb, intermediate limb, lower limb) as well as by bone section. This supports the approach of analyzing cut marks by their anatomical distribution on bones.

2. Equifinality II. The analytical method of Blumenschine, Selvaggio and Capaldo is problematic not only because it does not consider such a differential distribution of flesh, but also because of their definition of bone sections. They consider a bone specimen that has a fragment of epiphysis with a section of the near-epiphysis and mid-shaft to be an "epiphyseal specimen". Mid-shaft sections of such fragments that bear cut marks are classified as cutmarked "epiphyseal fragments", which gives the incorrect impression that the cut mark is situated on the epiphysis itself. The high survival of epiphyseal fragments attached to shaft sections and the high percentage of marks on these specimens will result in a relatively high number of "epiphyseal fragments" showing marks. Thus, the actual distribution of marks according to bone section is not properly represented. This is of real consequence when evaluating different models of hominid carcass acquisition and processing behavior. For instance, the availability of scraps of flesh from mid-shaft sections of limb bones first consumed by lions has been shown to be rather limited (see above). Implications vis-a-vis a hypothesis of lion followed by hominin consumption would differ if a specimen conserving part of the epiphysis with cut marks on the mid-shaft was classified as a "cut-marked epiphyseal fragment" rather than a "cut-marked mid-shaft fragment". Domínguez-Rodrigo (1997a,b, 1999) argues for a more precise classification of cut mark location that does not lump together mid-shafts and epiphyses. When using a method that incorporates such a distinction (element type and bone section), equifinality is reduced, and it is possible to formulate and successfully test alternative hypotheses of primary and secondary access to fleshed or defleshed carcasses (Domínguez-Rodrigo, 1997a, 2002). This can be done because access to fleshed carcasses is reflected in a high frequency of cut-marked specimens on mid-shafts, especially on upper limb bones (humerus and femur). When applied to FLK Zinj, results more closely match the experimental scenario simulating access to fleshed carcasses. Another effective visual method for minimizing any ambiguity regarding the anatomical location of cut marks is to draw them to scale on composite, whole-bone drawings (e.g., Bunn, 2001, 2007).

3. Additional evidence of access to meat by hominins. An approach analyzing cut mark location on the exact anatomical position and the anatomical distribution of flesh scraps has shown that the location of many cut marks on bones from the FLK Zinj are not related to flesh scrap survival on bones from felid kills (Domínguez-Rodrigo et al., 2007a).

4. Cut-marked upper limb bones are scarce in felid-consumed carcasses processed with stone tools. This has been documented by the only two experimental samples that have targeted replicating hominin scavenging from carnivore (felid) kills (Domínguez-Rodrigo, 1997a,b; Selvaggio, 1994; see also; Gidna et al., 2013). Selvaggio (1994:54-55) acknowledged that "limbs were abandoned by lions with little or no flesh on humeri and femora. Occasionally the skin was not completely consumed from the tibiae or the radius-ulnae and small scraps of flesh remained near the distal epiphyses." She further claimed that "long bones abandoned by large groups of carnivores were usually disarticulated from the carcass and while the marrow cavity remained intact, the bones were usually encountered completely defleshed" (Selvaggio, 1994:124).

Therefore, a high percentage of cut marks on upper limb bones from early sites would suggest defleshing of large muscle masses rather than the removal of scraps of flesh. Both studies (Selvaggio's and Dominguez-Rodrigo's) lead to the same conclusion with respect to carcasses processed by lions. Upper limb bones are utterly defleshed on most occasions. According to Selvaggio (1994: 122 ), this observation could also be extended to other predators and smaller carcasses: "Rarely were scraps of flesh available on proximal long bones abandoned by carnivores in the CarnivoreHominid sample."

\subsection{Mortality profiles}

1. If hominins were obtaining medium-sized carcasses - whether defleshed (Blumenschine, 1986) or partially fleshed (Pante et al., 2012) - from felid kills, it would be expected that these carcasses have the same mortality profiles as are generated by felids on this carcass size. Bunn and Pickering (2010) have provided an important advance in our understanding of how hominins acquired meat. Their work constitutes an improvement over the interpretation of primary access based taphonomic analyses alone. If hominins were scavenging carcasses from carnivores (passively or by confrontation), the age profile of this assemblage should be similar to the prey age profile of the implicated carnivores. For medium-sized carcasses, if scavenged from felids like lions, there should be an eclectic profile including subadults, prime adults, and more old adult individuals than occur proportionally in a typical bovid herd. Instead, the age profiles of the carcasses documented at FLK Zinj lie outside the predominant age profile of these felids and constitute one of the earliest documented cases of a prime-adult dominated assemblage, a pattern that in late Pleistocene archaeological sites in Europe and Africa is routinely attributed to efficient ambush hunting (Bunn and Pickering, 2010). This constitutes strong evidence that hominins were not passive scavengers but rather were hunting most of the carcasses that they accumulated at FLK Zinj.

\subsection{Bootstrapping and statistical treatment of data}

1. Chernick (1999) emphasized that when the original samples from which sampling and bootstrapping are performed are too small, the resulting central tendency values and reduced sample dispersion are not reliable. The use of bootstrapping techniques by anthropologists as a panacea for commonly small samples, without paying attention to this premise, may be misleading. Bootstrapping does not so much define central values as artificially decrease sample dispersion by enlarging sample size. Such an increase of sample size is done by resampling with replacement the original values of the sample (Fig. 4) in proportions (despite the randomness of the algorithm) similar to those of 


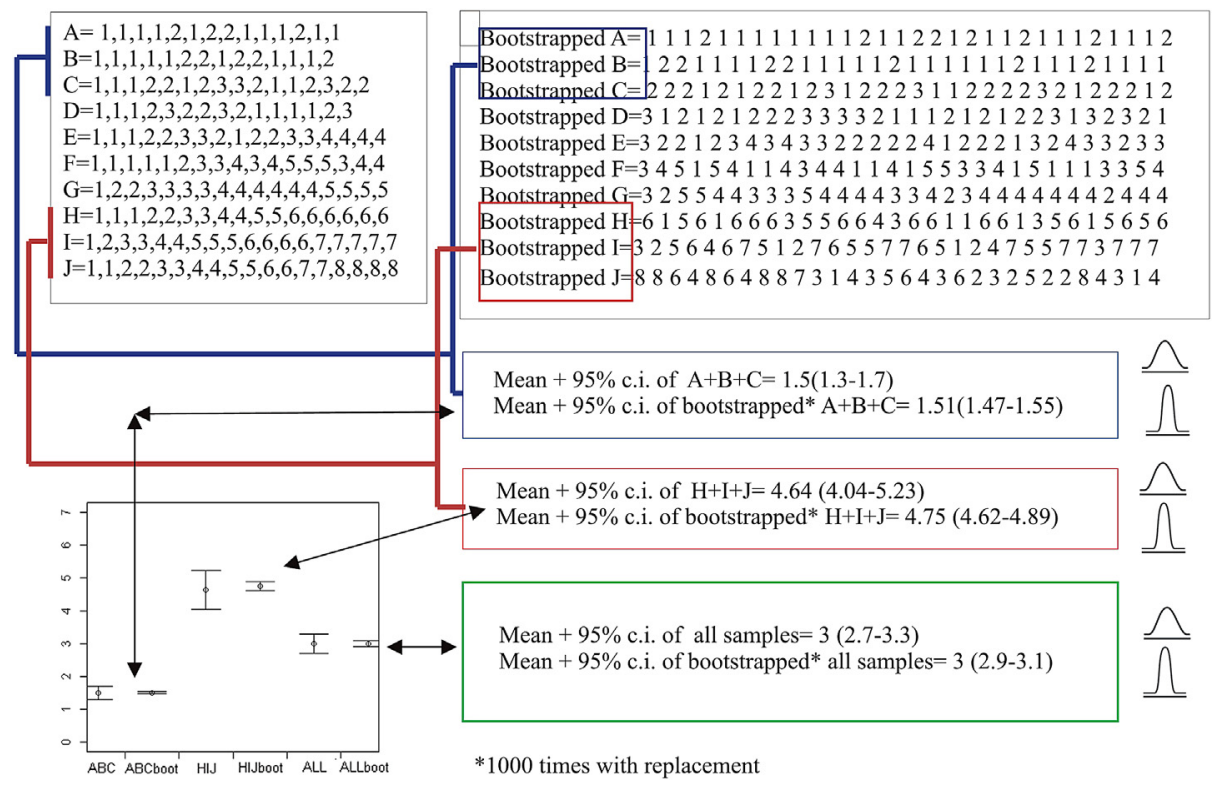

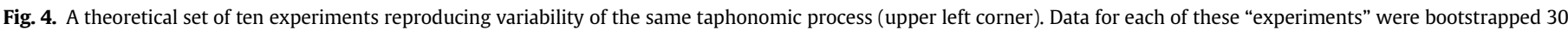

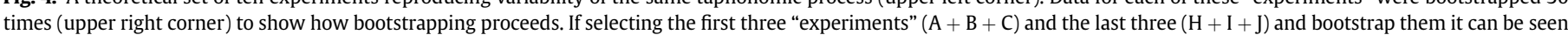

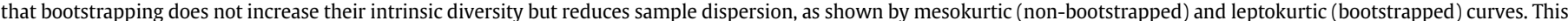

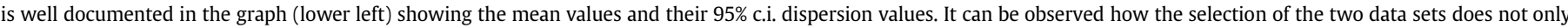

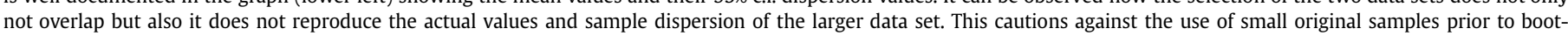

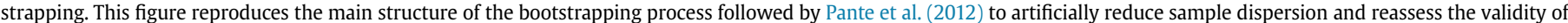
their experimental approach and interpretation of FLK Zinj.

the original sample. Therefore, if the original sample shows limited variability of data (or imperfectly represents the population), this will remain limited despite bootstrapping the sample thousands of times. Fig. 4 shows a theoretical example of this. A theoretical experimental set that reproduces variability in ten experiments reproducing the same process produces drastically bootstrapped estimates when using a very small number of experiments. The error bars showing confidence intervals of two partial sets of this theoretical sample show nonoverlapping different values (prone to be interpreted to derive from different models), and none of the bootstrapped experimental sets reproduce the central value or sample dispersion of the whole sample. This is a theoretical example that reemphasizes Chernick's (1999) caution with using originally small samples.

2. Pante et al.'s (2012) original experimental samples are small. Most of the experiment types used by them include less than 10 experiments, and if considering exactly the same type of model and experimental premise set, most data sets are lower than 5 experiments. This sample size is insufficient to provide reliable estimates of the range of variation of the replicated processes even if bootstrapped. Pante et al. (2012) have artificially reduced sample dispersion (as shown in Blumenschine, 1995) by providing a sequence of hierarchy-based bootstrapping approaches involving bootstraps of assemblages that come from an originally small sample of experiments and, therefore, are insufficient to represent the available experimental population. This creates an initial bias that is magnified by subsequent bootstrapping procedures, especially because this first function has reduced within-sample variability by bootstrapping only as many times a limited number of assemblages. For example, in the whole-bone-to-carnivore experiments, the sample used by Pante et al. (2012) is composed of 11 assemblages. The originally reduced sample can potentially show further reduced variability if the bootstrapping iteration excludes any of the original assemblages. Given the number of models containing $<10$ assemblages used by Pante et al. (2012), the function used by these authors contradicts Chernick's (1999) caution of using extremely small samples prior to bootstrap. This function also is a potential threat to the adequate representation of the sample by using such a limited number (random selection with replacement) of bootstrap iterations, which may not include all of the original assemblages, further reducing internal variability despite the artificially increased sample.

The specimens contained in each selected assemblage are thus subsequently bootstrapped $n$ number of times with replacement, thereby creating a magnified sample from an originally nonrepresentative sample of the model. The mean proportions of specimens that are modified in each bootstrap step are eventually jointly computed by being further bootstrapped 10,000 times. When this is done multiple times according to animal size and bone portion, the end result is a sample that shows a substantial reduction of its internal variability but without any guarantee that it represents either the existing set of experiments reproducing the model or the range of variability of the model population.

\section{Conclusions}

The previous section includes several arguments that invalidate the passive scavenging model. If all of these arguments could be falsified, then a niche might open again for passive scavenging strategies as a credible, valid explanation of early Pleistocene hominin carcass acquisition. Domínguez-Rodrigo and Pickering (2010) argued that, given the number of variables that could potentially be used in a conjoined way, modern taphonomy had to embrace the power of multivariate statistics and develop a multivariable approach, as the best way to overcome contradictions and equifinality produced by independent use of single variables. Regarding bone surface modifications, this means questioning the 
single-variable approach that for two decades has tested behavioral models and hominin and carnivore interactions with bone assemblages. In several of these single-variable models (e.g., when focusing solely on tooth mark frequencies), contradictions with other bone surface modification variables emerged. Most experimental models that tried to replicate multi-patterned interpretations of FLK Zinj based on a sequence started by felids, continued by hominins, and finished by other bone-crunching carnivores (namely, hyenas), never provided heuristic confirmation of this model when combining tooth, percussion and cut mark data. Some interpretations seem to be momentarily valid only when using one single variable at a time.

It is evident, from what we have shown in the present work, that such a narrow approach is obsolete due to its limitations and internal contradictions. When combining several types of bone surface modification, multivariate models provide further evidence that the felid-hominin-carnivore (hyena) interpretation for FLK Zinj is not sustainable. Pante et al. (2012) argued that bootstrapped versions of their single-variable models re-validated these, without solving any of the contradictions pointed out in the present work. We argued that bootstrapped versions of sample sizes that were originally too small $(n \leq 10)$ are statistically not warranted (Chernick, 1999) and that they did not provide a holistic solution when combining all types of bone surface modifications. The multivariate approach provided in the present work (MDA and MXDA) produced a highly successful two-factor solution, which was able to account for more than $90 \%$ of sample variance, and which classified FLK Zinj, when considering cut, percussion and tooth marks together, within the range of variation of the $\mathrm{H}-\mathrm{C}$ experimental set replicating primary access of hominins to fleshed carcasses. We have also shown that such access differs statistically from that where felids are the primary consumers and enable access to partially fleshed carcasses, as also implied by Pante et al. (2012). Both the multivariate approach, as well as the bootstrapped samples of experiments replicating secondary access and Upper Pleistocene sites where primary access is taphonomically defended, show that hominins did not acquire resources initially defleshed by any carnivore, at least not with a frequency that is detectable taphonomically. Therefore, we conclude that assumptions about the heuristics of single-variable models of bone surface modifications are invalidated and that the simultaneous use of all mark types provides further support for interpretations of primary access to carcasses by hominins at FLK Zinj, probably via hunting (Bunn and Pickering, 2010).

\section{Acknowledgements}

We thank COSTECH and the Antiquities Unit (Ministry of Natural Resources and Tourism) of Tanzania for permission to conduct research at Olduvai. We appreciate the major funding provided by the Spanish Ministry of Science and Innovation through the project I + D HAR2010-18952-C02-01, the Comunidad de Madrid through the S2010/BMD-2330 I + D project, and from the Ministry of Culture through the archaeological projects abroad program. We are very thankful to the comments made by two anonymous reviewers.

\section{References}

Ashley, G.M., Barboni, D., Dominguez-Rodrigo, M., Bunn, H.T., Mabulla, A.Z.P., DiezMartin, F., Barba, R., Baquedano, E., 2010. A spring and woodland: new paleoenvironmental reconstruction of FLK-Zinj, Olduvai Gorge, Tanzania. Quaternary International 74, 304-314.

Baquedano, E., Domínguez-Rodrigo, M., Musiba, C., 2012. An experimental study of large mammal bone modification by crocodiles and its bearing on the interpretation of crocodile predation at FLK Zinj and FLK NN3. Journal of Archaeological Science 39, 1728-1737.
Blasco, M.F., 1995. Hombres y Fieras. Estudio Zooarqueológico y Tafonómico del Yacimiento del Paleolítico Medio de la Cueva de Gabasa 1 (Huesca). Monografías de la Universidad de. Zaragoza, Zaragoza.

Blumenschine, R.J., 1986. Early Hominid Scavenging Opportunities. Implications of Carcass Availability in the Serengeti and Ngorongoro Ecosystems. In: Oxford: B.A.R. International Series, p. 283.

Blumenschine, R.J., 1988. An experimental model of the timing of hominid and carnivore influence on archaeological bone assemblages. Journal of Archaeological Science 15, 483-502.

Blumenschine, R.J., 1991. Hominid carnivory and foraging strategies, and the socioeconomic function of early archaeological sites. Philosophical Transactions of the Royal Society (London) 334, 211-221.

Blumenschine, R.J., 1995. Percussion marks, tooth marks and the experimental determinations of the timing of hominid and carnivore access to long bones at FLK Zinjanthropus, Olduvai Gorge, Tanzania. Journal of Human Evolution 29, 21-51.

Blumenschine, R.J., Masao, F.T., 1991. Living sites at Olduvai Gorge, Tanzania? Preliminary landscape archaeology results in the basal Bed II lake margin zone. Journal of Human Evolution 21, 451-462.

Blumenschine, R.J., Pobiner, B., 2006. Zooarchaeology and the ecology of oldowan hominid carnivory. In: Ungar, P. (Ed.), Evolution of the Human Diet: the Known, the Unknown and the Unknowable. Oxford University Press, Oxford, pp.167-190.

Blumenschine, R.J., Prassack, K., Kreger, C.D., Pante, M., 2007. Carnivore tooth marks, microbial bioerosion and the invalidation of Domínguez-Rodrigo \& Barba's (2006) test of Oldowan hominid scavenging behavior. Journal of Human Evolution 53, 420-426.

Blumenschine, R.J., Stanistreet, I.G., Njau, J.K., Bamford, M.K., Masao, F.T., Albert, R.M., Stollhofen, H., Andrews, P., Prassack, K.A., McHenry, L.J., FernándezJalvo, Y., Camilli, E.L., Ebert, J.I., 2012. Environments and hominin activities across the FLK Peninsula during Zinjanthropus times (1.84 Ma), Olduvai Gorge, Tanzania. Journal of Human Evolution 63, 364-383.

Booth, J.G., Sarkar, S., 1998. Monte Carlo approximation of bootstrap variances. The American Statistician 52, 1594-1610.

Bunn, H.T., 1981. Archaeological evidence for meat-eating by Plio-Pleistocene hominids from Koobi Fora and Olduvai. Nature 291, 574-577.

Bunn, H.T., 1982. Meat-eating and Human Evolution: Studies on the Diet and Subsistence Patterns of Plio-Pleistocene Hominids in East Africa (Ph. dissertation). University of California, Berkeley.

Bunn, H.T., 1983. Evidence on the diet and subsistence patterns of Plio-Pleistocene hominids at Koobi Fora, Kenya, and at Olduvai Gorge, Tanzania. In: CluttonBrock, J., Grigson, C. (Eds.), Animals and Archaeology: Hunters and their Prey, B.A.R. International Series, vol. 163, pp. 21-30.

Bunn, H.T., 2001. Hunting, power scavenging, and butchering by Hadza Foragers and by Plio-Pleistocene Homo. In: Stanford, C.B., Bunn, H.T. (Eds.), Meat-eating and Human Evolution. Oxford University Press, Oxford, pp. 199-218.

Bunn, H.T., 2007. Meat made us human. In: Ungar, P.S. (Ed.), Evolution of the Human Diet. Oxford University Press, Oxford, pp. 191-211.

Bunn, H.T., Kroll, E.M., 1986. Systematic butchery by Plio-Pleistocene hominids at Olduvai Gorge, Tanzania. Current Anthropology 27, 431-452.

Bunn, H.T., Kroll, E.M., 1988. Fact and fiction about the FLK Zinjanthropus floor: data, arguments, and interpretations (reply to L.R. Binford). Current Anthropology 29 (1), 135-149.

Bunn, H.T., Pickering, T.R., 2010. Bovid mortality profiles in paleoecological context falsify hypotheses of endurance running-hunting and passive scavenging by early Pleistocene hominins. Quaternary Research 74, 395-404.

Bunn, H.T., Mabulla, A.Z.P., Domínguez-Rodrigo, M., Ashley, G.M., Barba, R., DiezMartin, F., Remer, K., Yravedra, J., Baquedano, E., 2010. Was FLK North levels 1-2 a classic "living floor" of Oldowan hominins or a taphonomically complex palimpsest dominated by large carnivore feeding behavior? Quaternary Research 74, 355-362.

Cáceres, I., Anconetani, P., 1997. Procesos tafonómicos del nivel Solutrense de la Cueva de Higueral de Motillas (cádiz). Zephirus 50, 37-50.

Capaldo, S.D., 1995. Inferring Hominid and Carnivore Behavior from Dual-patterned Archaeological Assemblages (Ph. D. thesis). Rutgers University, New Brunswick.

Capaldo, S.D., 1997. Experimental determinations of carcass processing by PlioPleistocene hominids and carnivores at FLK 22 (Zinjanthropus), Olduvai Gorge, Tanzania. Journal of Human Evolution 33, 555-597.

Capaldo, S.D., 1998a. Methods, marks and models for inferring hominid and carnivore behaviour. Journal of Human Evolution 35, 323-326.

Capaldo, S.D., 1998b. Simulating the formation of dual-patterned archaeofaunal assemblages with experimental control simples. Journal of Archaeological Science 35, 311-330.

Cavallo, J.A., 1998. Tree-cached Leopard Kills and Early Hominid Foraging Strategies (Ph.D. dissertation). Rutgers, The State University of New Jersey.

Chernick, M.R., 1999. Bootstrap Methods. A Practicioner's Guide. Wiley, New York.

Domínguez-Rodrigo, M., 1997a. Meat-eating by early hominids at the FLK 22 Zinjanthropus site, Olduvai Gorge, Tanzania: an experimental approach using cut mark data. Journal of Human Evolution 33, 669-690.

Domínguez-Rodrigo, M., 1997b. A reassessment of the study of cut mark patterns to infer hominid manipulation of fleshed carcasses at the FLK Zinj 22 site, Olduvai Gorge, Tanzania. Trabajos de Prehistoria 54, 29-42.

Domínguez-Rodrigo, M., 1999. Flesh availability and bone modification in carcasses consumed by lions. Palaeogeography, Palaeoclimatology and Palaeoecology 149 , $373-388$.

Domínguez-Rodrigo, M., 2002. Hunting and scavenging by early humans: the state of the debate. Journal of World Prehistory 16, 1-54. 
Domínguez-Rodrigo, M., 2009. Are all Oldowan sites palimpsests? If so, what can they tell us of hominin carnivory? In: Hovers, E., Braun, D. (Eds.), Interdisciplinary Approaches to the Oldowan. Springer, New York, pp. 129-147.

Domínguez-Rodrigo, M., Pickering, T.R., 2003. Early hominids, hunting and scavenging: a summary of the discussion. Evolutionary Anthropology 12, 275-282.

Domínguez-Rodrigo, M., Barba, R., 2006. New estimates of tooth marks and percussion marks from FLK Zinj, Olduvai Gorge (Tanzania): the carnivore-hominidcarnivore hypothesis falsified. Journal of Human Evolution 50, 170-194.

Domínguez-Rodrigo, M., Barba, R., 2007. Five more arguments to invalidate the passive scavenging version of the carnivore-hominid-carnivore model: a reply to Blumenschine et al., (2007). Journal of Human Evolution 53, 427-433.

Domínguez-Rodrigo, M., Barba, R., Egeland, C.P., 2007a. Deconstructing Olduvai. Springer, New York.

Domínguez-Rodrigo, M., Egeland, C.P., Pickering, T.R., 2007b. Models of passive scavenging by early hominids: problems arising from equifinality in carnivore tooth mark frequencies and the extended concept of archaeological palimpsests. In: Pickering, T.R., Toth, N., Shick, K. (Eds.), Breathing Life into Fossils: Taphonomic Studies in Honor of C.K. ("Bob") Brain. Stone Age Institute Press, Gosport, Indiana, pp. 255-268.

Domínguez-Rodrigo, M., de Juana, S., Galán, A.B., Rodríguez, M., 2009. A new protocol to differentiate trampling marks from butchery cut marks. Journal of Archaeological Science 36, 2643-2654.

Domínguez-Rodrigo, M., Pickering, T.R., 2010. A multivariate approach for discriminating bone accumulations created by spotted hyenas and leopards: harnessing actualistic data from East and Southern Africa. Journal of Taphonomy 8, 155-179.

Domínguez-Rodrigo, M., Pickering, T.R., Bunn, H.T., 2010a. Configurational approach to identifying the earliest hominin butchers. Proceedings of the National Academy of Sciences of the United States of America 107 (49), 20929-20934.

Domínguez-Rodrigo, M., Bunn, H.T., Mabulla, A.Z.P., Ashley, G.M., Diez-Martin, F. Barboni, D., Prendergast, M.E., Yravedra, J., Barba, R., Sánchez, A., Baquedano, E., Pickering, T.R., 2010b. New excavations at the FLK Zinjanthropus site and its surrounding landscape and its behavioral implications. Quaternary Research 74, $315-332$.

Domínguez-Rodrigo, M., Mabulla, A.Z.P., Bunn, H.T., Diez-Martin, F., Baquedano, E., Barboni, D., Barba, R., Domínguez-Solera, S., Sanchez, P., Ashley, G.M., Yravedra, J., 2010c. Disentangling hominin and carnivore activities near a spring at FLK North (Olduvai Gorge, Tanzania). Quaternary Research 74, 363-375.

Domínguez-Rodrigo, M., Pickering, T.R., Bunn, H.T., 2011a. Reply to McPherron et al: Doubting Dikika is about data not paradigms. Proceedings of the National Academy of Sciences of the United States of America 108 (21), E117. http:// dx.doi.org/10.1073/pnas.1104647108.

Domínguez-Rodrigo, M., Pickering, T.R., Bunn, H.T., 2011b. Some critical comments on "The origins of stone tool technology". Philosophical Transactions of the Royal Society B 366, 1028-1037 http://dx.doi.org/10.1098/rstb.2010.0350.

Efron, B., 1987. Better bootstrap confidence intervals. Journal of the American Statistical Association 82, 171-200.

Fisher, J.W., 1995. Bone surface modification in zooarchaeology. Journal of Archaeological Method and Theory 1, 7-65.

Galán, A.B., de Juana, S., Domínguez-Rodrigo, M., 2009. A new experimental study on percussion marks and notches and their bearing on the interpretation of hammerstone-broken faunal assemblages. Journal of Archaeological Science 36 $776-784$.

Gidna, A., Kisui, A.B., Domínguez-Rodrigo, M., 2013. An ecological neo-taphonomic study of carcass consumption in Tarangire National Park (Tanzania) and its relevance for human evolutionary biology. Quaternary International (in press).

Hair, J.F., Anderson, R.E., Tatham, R.L., Black, W.C., 1998. Multivariate Data Analyses, Prentice Hall, Englewood Cliffs.

Hall, P., 1992. The Bootstrap and Edgeworth Expansion. Springer, New York.

Hastie, T.J., Tibshirani, R.J., 1996. Discriminant analysis by Gaussian mixtures. Journal of the Royal Statistical Society Series B 58, 158-176.

De Juana, S., Galán, A., Domínguez-Rodrigo, M., 2010. Taphonomic identification of cut marks made with lithic handaxes: an experimental study. Journal of Archaeological Science 37, 1841-1850.
Ma, J., He, X., 2008. A fast fixed-point BYY harmony learning algorithm on Gaussian mixture with automated model selection. Pattern Recognition Letters 29, 701 711.

Marín-Arroyo, A.B., 2004. Análisis arqueozoológico, tafonómico y de distribución espacial de la fauna de mamíferos de la cueva de la Fragua (Santoña, Cantabria). Santander, Edit TGD.

Njau, J., 2012. Reading Pliocene bones. Science, 46-47.

Oliver, J.S., 1994. Estimates of hominid and carnivore involvement in the FLK Zinjanthropus fossil assemblage: some socioecological implications. Journal of Human Evolution 27, 267-294.

Pante, M.C., Blumenschine, R.J., Capaldo, S.D., Scott, R.S., 2012. Validation of bone surface modification models for inferring hominin and carnivore feeding interactions, with reapplication to FLK 22, Olduvai Gorge, Tanzania. Journal of Human Evolution 63, 395-407.

Pattengale, N.D., Alipour, M., Bininda-Emonds, O.R., Moret, B.M., Stamatakis, A., 2010. How many bootstrap replicates are necessary? Journal of Computational Biology 17, 337-354.

Pickering, T.R., Domínguez-Rodrigo, M., 2006. The acquisition and use of large mammal carcasses by Oldowan hominins in Eastern and Southern Africa: selected review and assessment. In: Toth, N., Schick, K. (Eds.), The Oldowan: Studies into the Origins of Human Technology. Stone Age Institute Press, Bloomington, pp. 113-128.

Pobiner, B.L., 2007. Hominin-carnivore Interactions: Evidence from Modern Carnivore Bone Modification and Early Pleistocene Archaeofaunas (Koobi Fora, Kenya; Olduvai Gorge, Tanzania) (Ph.D. dissertation). Rutgers University.

Rausch, J.R., Kelly, K., 2009. A comparison of linear and mixture models for discriminant analysis under non-normality. Behaviour Research Methods 41, 85-98.

Schaller, G.B., 1972. The Serengeti Lion. University of Chicago Press, Chicago.

Selvaggio, M.M., 1994. Identifying the Timing and Sequence of Hominid and Carnivore Involvement with Plio-Pleistocene Bone Assemblages from Carnivore Tooth Marks and Stone-tool Butchery Marks on Bone Surfaces (Unpublished Ph. D. dissertation). Rutgers University.

Selvaggio, M.M., 1998a. Concerning the three stage model of carcass processing at FLK Zinjanthropus: a reply to Capaldo. Journal of Human Evolution 35, $313-315$.

Selvaggio, M.M., 1998b. Evidence for a three-stage sequence of hominid and carnivore involvement with long bones at FLK Zinjanthropus, Olduvai Gorge, Tanzania. Journal of Archaeological Science 25, 191-202.

Yravedra, J., 2005. Patrones de aprovechamiento de recursos animales en el Pleistoceno Superior de la Península Ibérica: estudio tafonómico y zooarqueológico de los yacimientos del Esquilleu, Amalda, cueva Ambrosio y la Peña de Estebanvela (Ph.D. dissertation). Universidasd Nacional de Educación a Distancia, Madrid, España.

Yravedra, J., 2006. Zooarqueología y Tafonomía en la Peña de Estebanvela (Ayllón, Segovia). In: Cacho, C., Ripoll, S., Muñoz, F.J. (Eds.), La Peña de Estebanvela (Ayllón-Segovia): grupos magdalenienses en el sur del Duero, Arqueología en Castilla y León, vol. 17, pp. 167-216.

Yravedra, J., 2007. Zooarqueología y Tafonomía en Cueva Ambrosio. Saguntum. SAGVNTVM 39, 63-82.

Yravedra, J., 2010. A taphonomic perspective on the origins of the faunal remains from Amalda Cave (Spain). Journal of Taphonomy 8, 301-334.

Yravedra, J., 2013. Análisis tafonómico de los macromamíferos del yacimiento paleolítico de Covalejos (Velo de los Piélagos, Cantabria, España) (in press).

Yravedra, J., Gómez-Castanedo, A., 2010a. Tafonomía en Cueva Morín. Resultados preliminares de un estudio necesario. Zephirus LXVII, 69-90.

Yravedra, J., Gómez-Castanedo, A., 2010b. Zooarqueología y Tafonomía de un viejo conocido la Cueva del Otero. Espacio, Tiempo y Forma 3, 21-38.

Yravedra, J., Muñoz, E., Gómez-Castanedo, A., 2010. Estrategias de Subsistencia en el yacimiento del Ruso (Igollo, Camargo, Cantabria España). Espacio, Tiempo y Forma 3, 39-58.

Zieffler, A.S., Harring, J., Long, J.D., 2011. Comparing Groups. Randomization and Bootstrap Methods Using R. Wiley, New Jersey. 